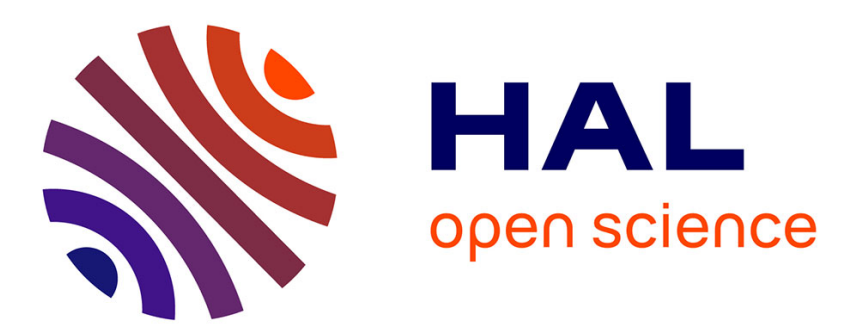

\title{
One year monitoring by FTIR of $\gamma$-irradiated multilayer film PE/EVOH/PE
}

Fanny Gaston, Nathalie Dupuy, Sylvain R A Marque, Magali Barbaroux, Samuel Dorey

\section{> To cite this version:}

Fanny Gaston, Nathalie Dupuy, Sylvain R A Marque, Magali Barbaroux, Samuel Dorey. One year monitoring by FTIR of $\gamma$-irradiated multilayer film PE/EVOH/PE. Radiation Physics and Chemistry, 2016, 125, pp.115-121. 10.1016/j.radphyschem.2016.03.010 . hal-01450848

\author{
HAL Id: hal-01450848 \\ https://hal.science/hal-01450848
}

Submitted on 12 Apr 2018

HAL is a multi-disciplinary open access archive for the deposit and dissemination of scientific research documents, whether they are published or not. The documents may come from teaching and research institutions in France or abroad, or from public or private research centers.
L'archive ouverte pluridisciplinaire HAL, est destinée au dépôt et à la diffusion de documents scientifiques de niveau recherche, publiés ou non, émanant des établissements d'enseignement et de recherche français ou étrangers, des laboratoires publics ou privés. 


\title{
One year monitoring by FTIR of $\gamma$-irradiated multilayer film $\mathrm{PE} / \mathrm{EVOH} / \mathrm{PE}$
}

\author{
Fanny Gaston a,b,d, Nathalie Dupuy ${ }^{\mathrm{a}, *}$, Sylvain R.A. Marque ${ }^{\mathrm{b}, \mathrm{c}, * *}$, Magali Barbaroux ${ }^{\mathrm{d}}$, \\ Samuel Dorey ${ }^{\mathrm{d}}$ \\ a Aix Marseille Université, LISA, EA4672, Equipe METICA, 13397 Marseille Cedex 20, France \\ ${ }^{\mathrm{b}}$ Aix Marseille Université, Institut de Chimie Radicalaire-UMR 7273, Case 551, 13397 Marseille cedex 20, France \\ ${ }^{c}$ Vorozhtsov Novosibirsk Institute of Organic Chemistry Office 312, 9 Prospect Academican Laurentiev, 630090 Novosibirsk, Russia \\ d Sartorius Stedim FMT S.A.S, Z.I. Les Paluds, Avenue de Jouques CS91051, 13781 Aubagne Cedex, France
}

H I G H L I G H T S

- $\gamma$-ray sterilization of single-use plastic bags for biotechnology and biopharmaceutical applications.

- Use of ATR-FTIR spectroscopy to monitor the modifications of $\gamma$-irradiated polymers over time.

- Interpretation and highlighting of slight spectral variations after multiple absorbed doses using chemometric methods.
G R A P H I C A L A B S T R A C T

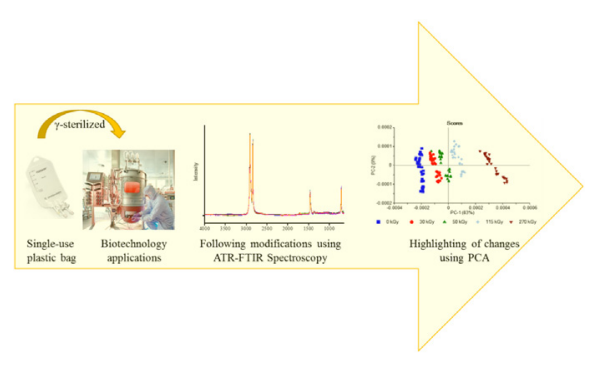

A B S T R A C T

The multilayer films made of polyethylene/polyethylene-co-vinyl alcohol/polyethylene are $\gamma$-irradiated for biopharmaceutical and biotechnological applications. The radiations generate changes in the polymer films. In this study, we focused on the modifications produced on the surface of materials by Fourier transformed infrared (FTIR) spectroscopy combined with chemometric treatments. Principal component analysis (PCA) allows the ordering of the surface modifications according to absorbed doses and the natural ageing. Results show the rising of the acid band and the variation of unsaturated compounds.

Keywords:

Fourier transform infrared spectroscopy

$\gamma$-irradiation

Polyethylene

Multilayer film

Principal component analysis

\section{Introduction}

Preventing cross-contamination, saving costs and increasing configuration flexibility make the adoption of single-use technologies very attractive for the biopharmaceutical industry. Stainless

\footnotetext{
*** Corresponding author at: Aix Marseille Université, Institut de Chimie Radicalaire-UMR 7273, Case 551, 13397 Marseille cedex 20, France.

E-mail addresses: nathalie.dupuy@univ-amu.fr (N. Dupuy), sylvain.marque@univ-amu.fr (S.R.A. Marque).
}

steel tanks are increasingly being replaced by plastic containers. The integrity and the security of bags are due to appropriate flexible and barrier polymeric materials, such as polyethylene (PE) and polyethylene-co-vinyl alcohol (EVOH), which are barrier to water vapor and oxygen, respectively (Goulas et al., 2003). Conventional stainless steel tanks are sterilized by steam sterilization by the end-users, whereas plastic containers, which have to be sterile as well, are sterilized by irradiation before delivery. Sterilization can induce modifications of materials, as reported in the literature (Traboulsi et al., 2012). Irradiation of polymeric materials has been proven to initiate radiation chemical reactions inside the 


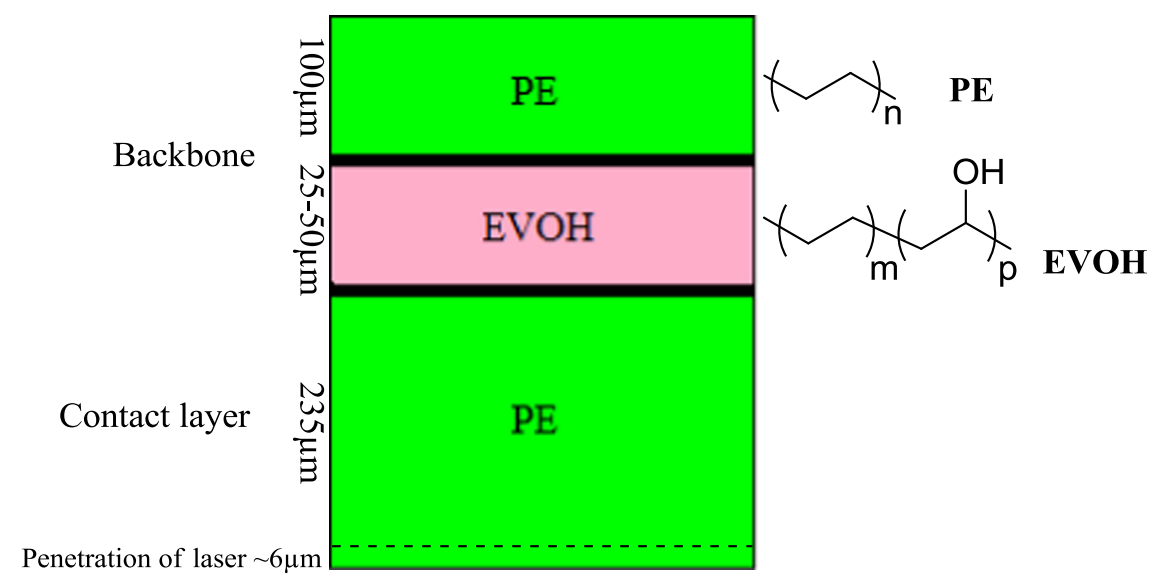

Fig. 1. Structures of film and polymers.

polymeric material, leading to either an increase or a decrease in the polymer molecular weight (Driffield et al., 2009; Suarez and Mano, 2001). The effects of $\gamma$-irradiation on polymers are well known (Hemmerich, 2000; Tidjani and Watanabe, 1995; Lacoste and Carlsson, 1992; Lacoste et al., 1991; Stoffers et al., 2004; Demertzis et al., 1999), whereas the effects of $\gamma$-irradiation on multilayer films have been little investigated (Goulas et al., 2003). In the case of the material discussed hereafter, the acidity of the stored solution increased after gamma irradiation. In another case oxidation of the solution occurred. Such observations denote the presence of acidic and oxidant compounds, which are issued either from modification of surface of the film or from the migration of by-products from core to surface. Along with the ageing induced by $\gamma$-irradiation, natural ageing of the film (Rjeb et al., 2000; Youssef et al., 2008) may also occur. A previous study using Electron Spin Resonance has highlighted the presence of radicals in a $\mathrm{PE} / \mathrm{EVOH} / \mathrm{PE}$ multilayer film during about 2 months (Audran et al., 2015). This material can be investigated either by transmission infrared spectroscopy which provides information on the composition of the three-layer film PE/EVOH/PE or by ATR which provides information on surface. The ATR technique is the more suitable approach to answer to our issues. Moreover, this technique will provide insights about the potential migration of by-product from the core to the surface of material over time. Though the classical absorbed dose for the biopharmaceutical industry ranges between 25 and $45 \mathrm{kGy}$ (Bioprocess International, 2008), absorbed doses up to $270 \mathrm{kGy}$ were investigated in order to emphasize the $\gamma$-irradiation effect and therefore to enhance the $\gamma$-ray induced modifications. The stability of the film was investigated over a 12 month period after irradiation. A chemometric method, Principal Component Analysis (PCA), was applied to enhance the weak variation in FTIR spectra due to the $\gamma$-irradiation of the multilayer film.

\section{Materials and methods}

\subsection{Film sample}

A multilayer film sample is composed of polyethylene (PE) and ethylene vinyl alcohol (EVOH): $\mathrm{PE} / \mathrm{EVOH} / \mathrm{PE}$, and has a total thickness of about $400 \mu \mathrm{m}$. The structure of the film, as well as those of the polymers, is depicted in Fig. 1. The different layers of this film contain additives, including at least an antioxidant (especially phenol and phosphite (Jeon et al., 2007; Bourges et al., 1992; Pospisil, 1993)) and antiblocking agents ( $<500$ ppm, so not detectable with ATR-FTIR), for their stabilization during the manufacturing process and during their shelf life. Only the internal layer, which will be in contact with the solution in the future applications, was investigated here. Moreover, recordings were performed over time, after $0,1,2,3,4,5,6,12$ months of ageing (T0, T1m, T2m, T3m, T4m, T5m, T6m, T12m). The measurements were performed on four lots. As they all afford the same observations, only one lot will be discussed in this article. The samples were stored according to customer requirements: not exposed to direct light and in a room with temperature around $27 \pm 5^{\circ} \mathrm{C}$.

\section{2. $\gamma$-irradiation}

Sheets of film (thickness of about $400 \mu \mathrm{m}$ ) were packed and wrapped in specific packaging (PE) and irradiated at room temperature in a ${ }^{60} \mathrm{Co} \gamma$-source. This ${ }^{60} \mathrm{Co} \gamma$-source provides a dose rate of $8-13 \mathrm{kGy} / \mathrm{h}$ - as given by the company Synergy Health Marseille (France) - affording doses of $30( \pm 1), 50( \pm 1), 115$ $( \pm 2)$ and $270( \pm 5) \mathrm{kGy}$. A sterilization cycle provides a dose of $25 \mathrm{kGy}$. The above mentioned doses are obtained after several sterilization cycles, including a non-controlled waiting time in non-controlled storage conditions between each cycle. The first analysis was performed on the film samples approximately 10 days after $\gamma$-irradiation.

\subsection{Fourier transform infrared spectroscopy (FTIR)}

Film samples were directly deposited onto the Bruker "Golden Gate" attenuated total reflectance accessory provided with a diamond crystal. The spectra for each film sample were recorded from 4000 to $650 \mathrm{~cm}^{-1}$, with $4 \mathrm{~cm}^{-1}$ resolution and 64 scans, on a Thermo Nicolet Avatar spectrometer equipped with a MCT/A detector, an Ever-Glo source, and a $\mathrm{KBr} /$ germanium beam splitter. The spectrometer was placed in an air-conditioned room at $21^{\circ} \mathrm{C}$. Three or five spectra were recorded for each sample to reduce the possible impact of film inhomogeneity. A background scan in air (under the same resolution and scanning conditions as those used for the samples) was carried out before three or five sets of acquisition. The ATR plate was cleaned in situ by scrubbing with an ethanol solution to remove any residual traces of the previous sample. Cleanliness was checked by recording a background spectrum. The penetration depth in the sample is only a few micrometers ${ }^{1}$.

\footnotetext{
${ }^{1}$ Harrick formula gives the penetration depth corresponding to a given wavenumber: with $d_{p}$, the penetration depth; $\lambda$, the given wavenumber; $n_{1}$, refractive index of sample $\left(n_{1}=1.5\right)$ for most organic materials, Liu et al. $(2013,2009) ; n_{2}$ refractive index of diamond crystal $\left(n_{2}=2.417\right) ; \theta$, angle of incidence of the beam relative to the normal of the diamond interior $\left(\theta=45^{\circ}\right)$. Penetration depth is around $6 \mu \mathrm{m}$ for $\lambda=700 \mathrm{~cm}^{-1}$, and around $0.3 \mu \mathrm{m}$ for $\lambda=4000 \mathrm{~cm}^{-1}$.
} 


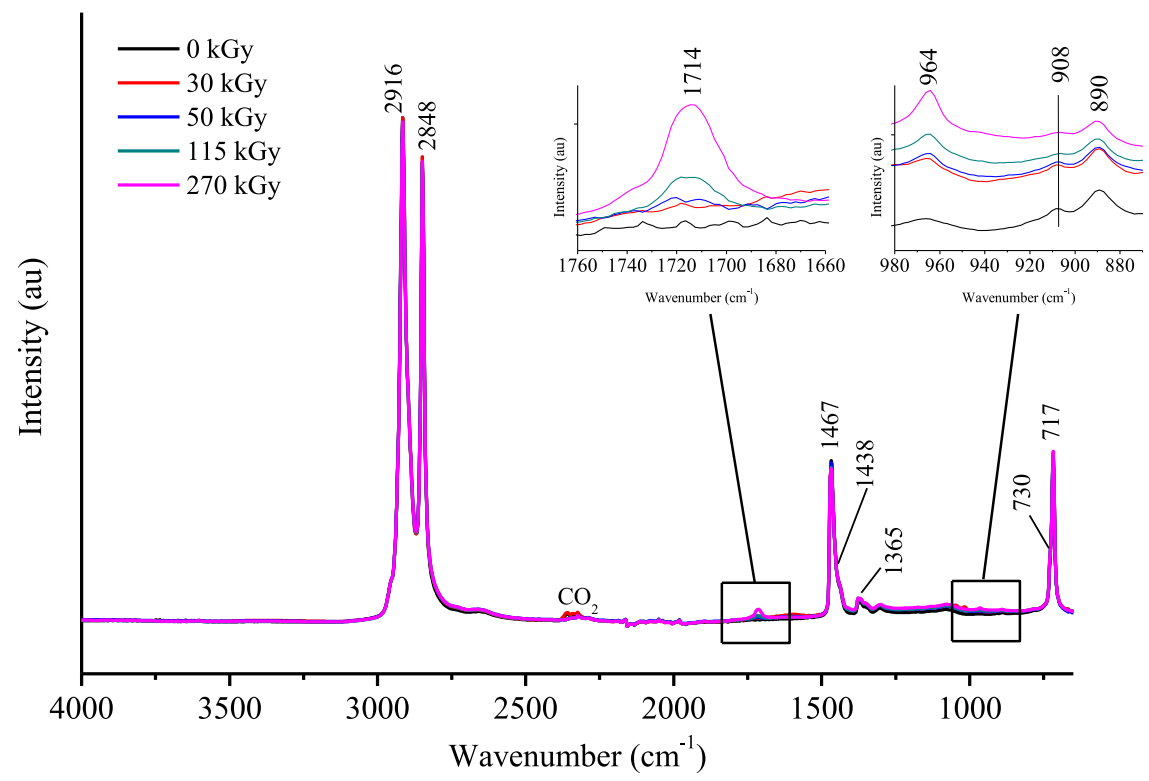

Fig. 2. Overlay of spectra for not sterilized and $\gamma$-irradiated PE. Inset: enlargement of carbonyl zone (left) and of trans alkene zone (right).

\subsection{Principal component analysis (PCA)}

Principal Component Analysis (Martens and Naes, 1989) is a multivariate technique acting in an unsupervised manner and it is used to analyze the inherent structure of the data. A mathematical procedure transforms a matrix of correlated variables into a new matrix of mutually uncorrelated variables called principal components (PC). PCs describe the variations amongst the objects, in decreasing order from the greatest to the smallest. There is no correlation between them. Each PC contains a part of the total information contained in the original data. In matrix representation, the model with a given number of components has the following equation:

$$
\mathrm{X}=\mathrm{T} \cdot \mathrm{P}^{\mathrm{T}}+\mathrm{E}
$$

where $\mathrm{T}$ is the scores matrix, $\mathrm{P}$ the loadings matrix and $\mathrm{E}$ the error matrix.

The data are grouped based on the similarities between samples after plotting two PCs relatively to each other (Kumar et al., 2014; Esbensen et al., 2002). The aim was to observe the impact of $\gamma$-irradiation on the internal PE layer. The variations (intensity and shift) of the FTIR peaks depending on the absorbed doses were investigated. For all PCAs, PE spectra were adjusted using the baseline correction and/or the smoothing Savitzky Golay algorithm.

\section{Results and discussion}

The $30 \mathrm{kGy}$ absorbed dose is obtained after a passage of about $3 \mathrm{~h}$ in front of the ${ }^{60} \mathrm{Co}$ source, the $50 \mathrm{kGy}$ absorbed dose after about $6 \mathrm{~h}$, and so on. As observed with the following results (Section 3.2), the differences between the 0, 30 and $50 \mathrm{kGy}$ doses are small, so it is difficult to discuss about the chemistry in these cases. Therefore, for the discussion, 115 and $270 \mathrm{kGy}$ absorbed doses are assumed to enhance the chemical processes occurring at the lower doses. This assumption is supported by the absence of any new rising signal in the FTIR spectra above the $50 \mathrm{kGy}$ dose.

\subsection{ATR-FTIR}

The effect of the absorbed dose from 0 (non-sterilized material) to $270 \mathrm{kGy}$ is displayed in Fig. 2. The main changes in signal are observed in the carboxylic acid zone (around $1714 \mathrm{~cm}^{-1}$ ) and in the trans alkene zone (between 880 and $980 \mathrm{~cm}^{-1}$ ). Enlargements of these zones show a variation depending on the absorbed dose (Fig. 2), emphasized by the PCA (vide infra). The peaks observed in the $730-700 \mathrm{~cm}^{-1}$ zone and in the $2920-2840 \mathrm{~cm}^{-1}$ zone do not show any variation with the absorbed dose. In ATR mode, the penetration depth of the infrared beam into the material is very small in the zone around $3000 \mathrm{~cm}^{-1}$, thus $\gamma$-irradiation induced variations do not result in significant spectral changes. Although crosslinking and chain scission events are expected to occur at significant extent (Dole, 1981; Dole et al., 1979; Dole and Patel, 1977), no significant changes on the IR signal of PE chain are detected in our experimental conditions. Nevertheless, some clues as trans vinylene group and vinyl end group suggest the occurrence of these events. The superposition of spectra at $270 \mathrm{kGy}$ for T0 and $\mathrm{T} 12 \mathrm{~m}$ is displayed in Fig. 1 Supplementary information and shows no change at first sight.

The IR assignments of the signals from the non-irradiated and irradiated PE layer are provided in Table 1 according to the literature (Traboulsi et al., 2012; Tidjani and Watanabe, 1995; Lacoste and Carlsson, 1992; Liu et al., 2011; Wool and Bretzlaff, 1986; Socrates; Tidjani and Arnaud, 1993; Cross et al., 1950; Boerio and Wirasate, 2007; Socrates; Lobo and Bonilla, 2003; Socrates; Giurginca et al., 2003; Socrates; Tidjani, 2000; Guadagno et al., 2001). Peaks at 2916 and $2848 \mathrm{~cm}^{-1}$ are ascribed to the antisymmetric and symmetric stretching of $-\mathrm{CH}_{2}$ - groups. Peaks included between 1470 and $1360 \mathrm{~cm}^{-1}$ are ascribed to the deformation of $-\mathrm{CH}_{2}-$ and $-\mathrm{CH}_{3}-$ groups.

In the zone of unsaturations, one can observe peaks at $964 \mathrm{~cm}^{-1}\left(\mathrm{R}_{1}-\mathrm{CH}=\mathrm{CH}-\mathrm{R}_{2}\right), 908 \mathrm{~cm}^{-1}\left(\mathrm{R}-\mathrm{CH}=\mathrm{CH}_{2}\right)$ whose areas vary and a peak at $890 \mathrm{~cm}^{-1}\left(\mathrm{R}_{1} \mathrm{R}_{2} \mathrm{C}=\mathrm{CH}_{2}\right)$ whose area does not vary, according to the absorbed doses. Peaks at $720-730 \mathrm{~cm}^{-1}$ are characteristic of long chains of $-\mathrm{CH}_{2}-$ in PE.

\section{2. $P C A$}

In the ATR-FTIR spectra, only in two zones (carboxylic acids, [1760-1660 $\left.\mathrm{cm}^{-1}\right]$, and unsaturated groups, [975-875 $\left.\left.\mathrm{cm}^{-1}\right]\right) \mathrm{a}$ change in the signal occurs. Outside of these two zones, the PCA does not reveal any change according to either the $\gamma$-absorbed dose or the natural ageing, which is illustrated in Fig. 3 with the chain length and crystallinity zone $\left(750-700 \mathrm{~cm}^{-1}\right)$. The 
Table 1

IR assignments of bands for PE spectra.

\begin{tabular}{|c|c|c|}
\hline Wavenumber $\left(\mathrm{cm}^{-1}\right)$ & Functional group & Type of vibration \\
\hline 2916 & $\nu-\mathrm{CH}_{2}-$ & Antisymmetric stretching (Traboulsi et al., 2012; Liu et al., 2011; Wool and Bretzlaff, 1986; Lobo and Bonilla, 2003) \\
\hline 2848 & $\nu-\mathrm{CH}_{2}^{-}$ & Symmetric stretching (Traboulsi et al., 2012; Liu et al., 2011; Wool and Bretzlaff, 1986; Lobo and Bonilla, 2003) \\
\hline 1739 & $\nu-\mathrm{C}=\mathrm{O}$ ester & Stretching (Liu et al., 2011; Socrates; Giurginca et al., 2003) \\
\hline 1732 & $\nu-\mathrm{C}=\mathrm{O}$ aldehyde & Stretching (Liu et al., 2011) \\
\hline $1705-1725$ & $\nu-C=O$ ketone & Stretching (Socrates) \\
\hline 1714 & $\nu-\mathrm{C}=\mathrm{O}$ carboxylic acid & $\begin{array}{l}\text { Stretching (Tidjani and Watanabe, 1995; Lacoste and Carlsson, 1992; Liu et al., 2011; Socrates; Tidjani, 2000; Guadagno } \\
\text { et al., 2001) }\end{array}$ \\
\hline $1467-1438$ & $\delta-\mathrm{CH}_{2-}^{-}$ & Deformation in the plane (Traboulsi et al., 2012; Liu et al., 2011; Lobo and Bonilla, 2003) \\
\hline 1365 & $\delta \mathrm{CH}_{3}$ & Deformation in the plane (Liu et al., 2011; Socrates; Boerio and Wirasate, 2007; Lobo and Bonilla, 2003) \\
\hline 964 & $\mathrm{R}_{1}-\mathrm{CH}=\mathrm{CH}-\mathrm{R}_{2}$ & $\begin{array}{l}\text { Trans vinylene group (Tidjani and Watanabe, 1995; Lacoste and Carlsson, 1992; Socrates; Tidjani and Arnaud, 1993; Cross } \\
\text { et al., 1950; Lobo and Bonilla, 2003) }\end{array}$ \\
\hline 908 & $\mathrm{R}-\mathrm{CH}=\mathrm{CH}_{2}$ & $\begin{array}{l}\text { Vinyl end group (Tidjani and Watanabe, 1995; Lacoste and Carlsson, 1992; Liu et al., 2011; Socrates; Tidjani and Arnaud, } \\
\text { 1993; Cross et al., 1950; Lobo and Bonilla, 2003) }\end{array}$ \\
\hline 890 & $\mathrm{R}_{1} \mathrm{R}_{2} \mathrm{C}=\mathrm{CH}_{2}$ & $\begin{array}{l}\text { Vinylidene group (Tidjani and Watanabe, 1995; Lacoste and Carlsson, 1992; Socrates; Tidjani and Arnaud, 1993; Cross } \\
\text { et al., 1950; Lobo and Bonilla, 2003) }\end{array}$ \\
\hline 730 (shoulder) & $\delta-\mathrm{CH}_{2-}-$ & Inner rocking vibration of $-\mathrm{CH}_{2}-$ in the crystalline part (Liu et al., 2011; Wool and Bretzlaff, 1986; Lobo and Bonilla, 2003) \\
\hline 717 & $\delta-\mathrm{CH}_{2}-$ & $\begin{array}{l}\text { Inner rocking vibration of }-\mathrm{CH}_{2}-\text { in the amorphous part (Liu et al., 2011; Wool and Bretzlaff, 1986; Lobo and Bonilla, } \\
\text { 2003) }\end{array}$ \\
\hline
\end{tabular}

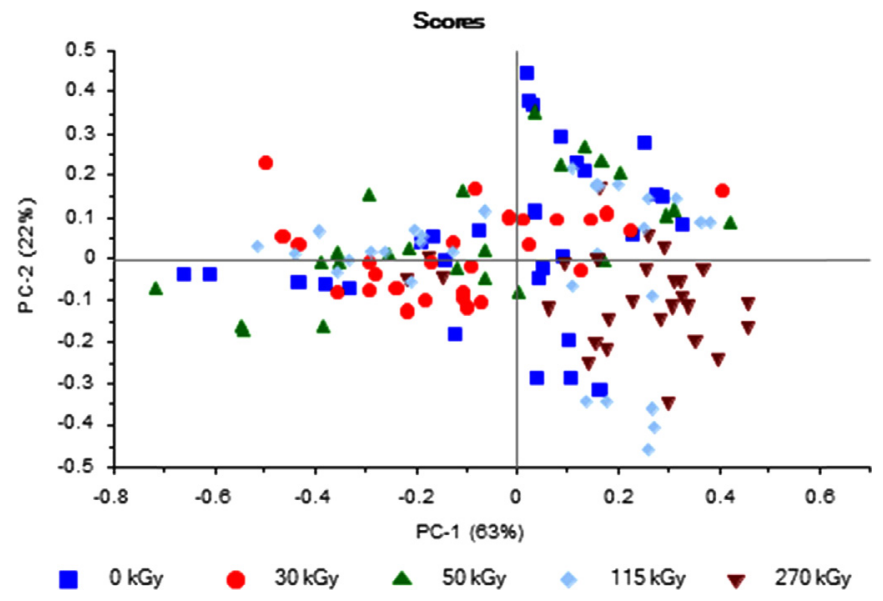

Fig. 3. PCA of PE spectra at all absorbed doses $\left(750-700 \mathrm{~cm}^{-1}\right)$. Spectra are adjusted with baseline correction and Standard Normal Variation (SNV) correction.

occurrence of these events is below the detection limit of the technique $(\sim 5 \%)$.

\subsubsection{Carbonyl zone}

The PCA displayed in Fig. 4 concerns the carbonyl zone [1760-1660 $\left.\mathrm{cm}^{-1}\right]$. It is performed on 152 spectra, which represent the effects of all absorbed doses and ageing.

For this zone, PE spectra are adjusted with baseline correction and smoothing Savitzky Golay algorithm. The first principal component (PC1) represents 99\% of the total variance of the modification of spectra, and changes are correlated to the absorbed dose. The impact of the absorbed dose on the film is not homogeneous: there is an overlap between the $30 \mathrm{kGy}$ irradiated group, the $50 \mathrm{kGy}$ irradiated group and the non-irradiated group. The irradiation impact is significant above $115 \mathrm{kGy}$. When the absorbed dose increases, there is an increase in the intensity of the peak at $1714 \mathrm{~cm}^{-1}$, in the zone of carbonyl functions such as carboxylic acid (1700-1740 cm-1) (Socrates), ketone (1705-1725 $\mathrm{cm}^{-1}$ ) (Klepac et al., 2014), aldehyde (1720-1740 $\mathrm{cm}^{-1}$ ) (Socrates) and/or ester (1725-1750 $\mathrm{cm}^{-1}$ ) (Socrates). This means that oxidation of PE (Tidjani and Watanabe, 1995; Lacoste and Carlsson, 1992; Liu et al., 2011; Buttafava et al., 2007; Kaci et al., 2008; Taniike et al., 2014 ) occurs under $\gamma$-irradiation. Some authors identified the presence of carboxylic acid by FTIR spectroscopy combined with chemical derivatization (Tidjani and Watanabe, 1995; Lacoste and Carlsson, 1992; Lacoste et al., 1991; Tidjani, 2000), highlighting the peak at $1714 \mathrm{~cm}^{-1}$ as the fingerprint of $\mathrm{C}=\mathrm{O}$ in acid (Tidjani and Watanabe, 1995; Lacoste and Carlsson, 1992; Liu et al., 2011; Socrates; Tidjani, 2000; Guadagno et al., 2001). Consequently, formation of acid was assumed based on these grounds. ${ }^{2}$ However, the presence of ketone, aldehyde or ester cannot be disregarded, due to the shoulder and the non-symmetrical peak at $1714 \mathrm{~cm}^{-1}$ observed in Fig. 2 (enlargement of carbonyl zone) and in Fig. 4b, respectively. No signal at $1780 \mathrm{~cm}^{-1}$ corresponding to the lactone is observed. The second principal component (PC2) represents only $1 \%$ of the total variance of the modification of spectra and does not deserve further comment. The variance of this component is due to the uncertainty in the measurements and it cannot be coupled with the natural ageing.

There is no variation over time, which means that there is no migration of by-products from the core layer. Furthermore, the generation of carboxylic acid occurs during the $\gamma$-irradiation and then remains steady. These results do not deserve further comment as agree with literature (Lacoste and Carlsson, 1992; Liu et al., 2011; Tidjani and Arnaud, 1993; Gugumus, 2000).

\subsubsection{Unsaturations zone}

The PCA displayed in Fig. 5 concerns the unsaturations zone [975-875 $\mathrm{cm}^{-1}$ ]. It is performed on 152 spectra, which represent the effects of all absorbed doses and ageing.

The first principal component (PC1) accounts for $83 \%$ of the total variance of the modification of spectra, and changes with the absorbed dose. The second principal component (PC2) represents $9 \%$ of the total variance of the modification of spectra, and corresponds to the natural ageing.

PC1 (83\%, Fig. 5b and c) reveals several modifications in the PE chain: peak at $964 \mathrm{~cm}^{-1}\left(-\mathrm{R}_{1}-\mathrm{CH}=\mathrm{CH}-\mathrm{R}_{2}\right.$, trans vinylene groups), which increases when the absorbed dose increases, and peak at $908 \mathrm{~cm}^{-1}$ (-R-CH $=\mathrm{CH}_{2}$, vinyl end groups), which decreases when the absorbed dose increases. The area of the peak corresponding to the vinylidene groups at $890 \mathrm{~cm}^{-1} \quad\left(\mathrm{R}_{1} \mathrm{R}_{2} \mathrm{C}=\mathrm{CH}_{2}\right.$, vinylidene groups) does not vary (Fig. $5 \mathrm{c}$ ). These observations are in agreement with literature (Tidjani and Watanabe, 1995; Lacoste and Carlsson, 1992; Tidjani and Arnaud, 1993; Kaci et al., 2008; Tabb et al., 1975). The formation of unsaturated groups is monotonic with the absorbed dose. The irradiation generates trans vinylene

\footnotetext{
${ }^{2}$ Unfortunately, the other characteristic peak of the carboxylic acid function $\left(1265 \mathrm{~cm}^{-1}\right)$ is not detected. As the concentration of carboxylic acid is very small and as the $\mathrm{C}-\mathrm{O}$ stretching gives a signal less intense than the $\mathrm{C}=\mathrm{O}$ stretching, this peak is unlikely to be detected even using PCA.
} 


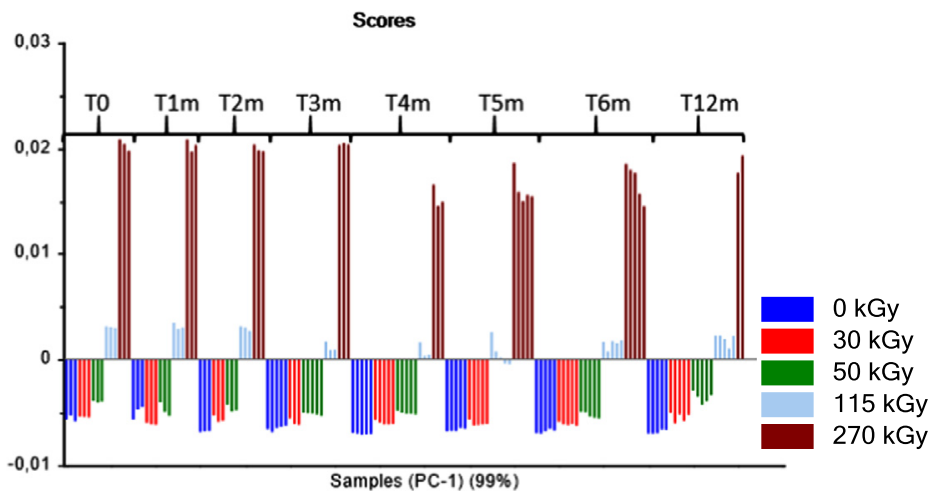

a)

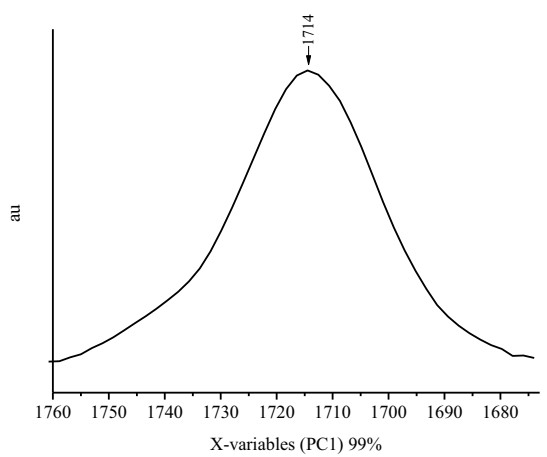

b)

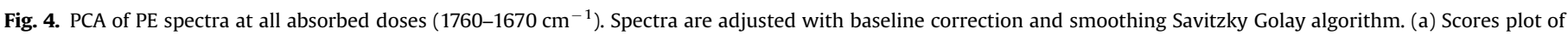
PCA. (b) Loading plot of PC1.

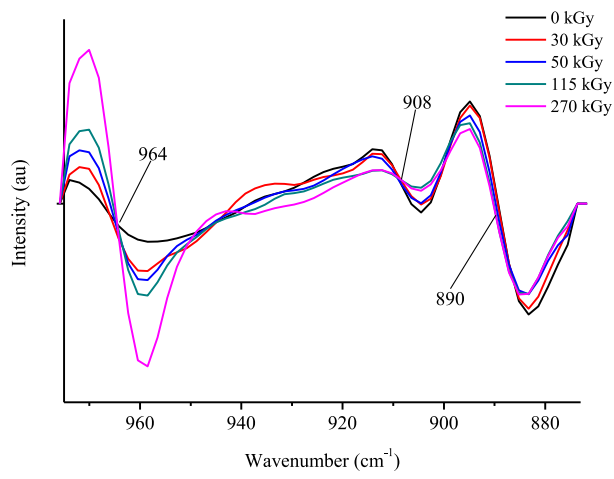

a)

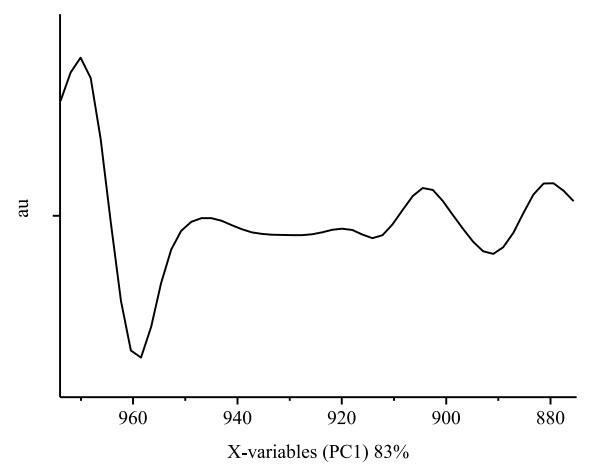

c)

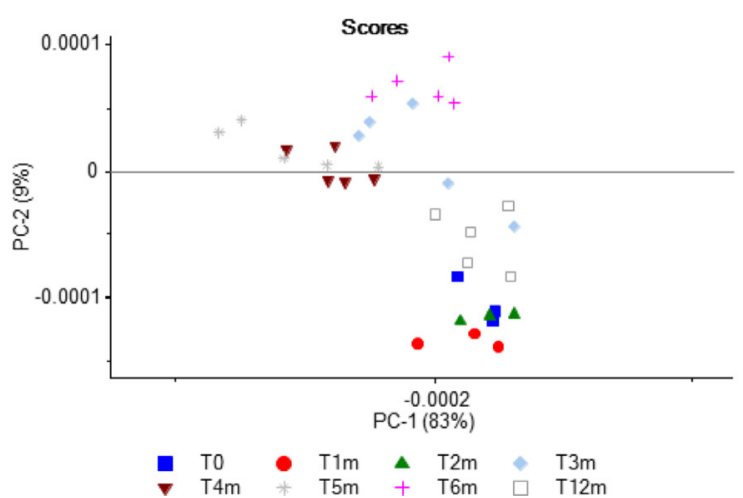

e)

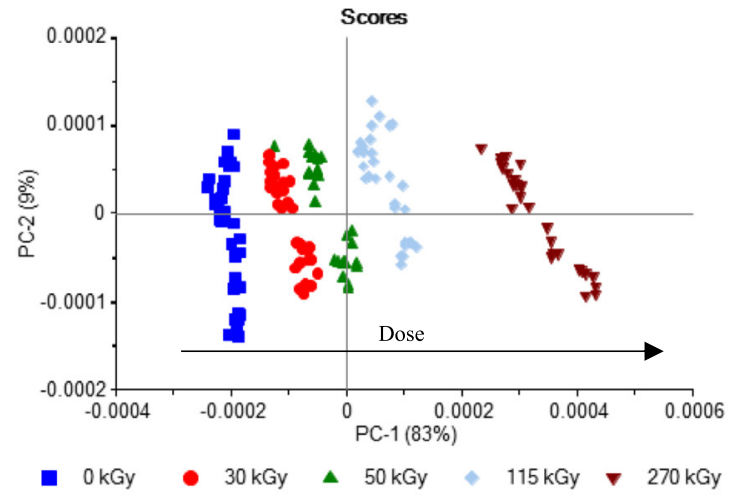

b)

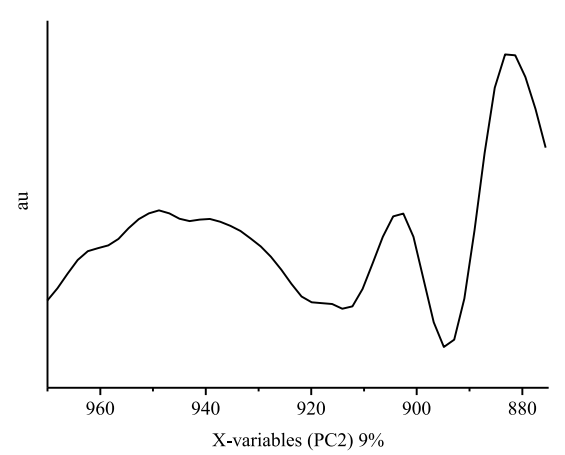

d)

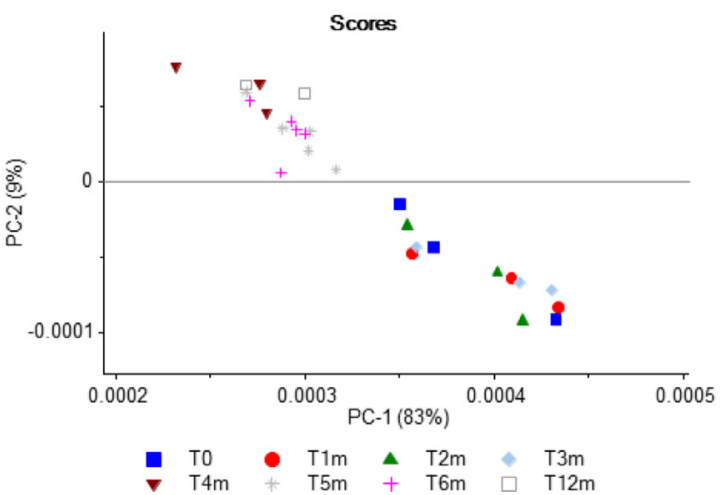

f)

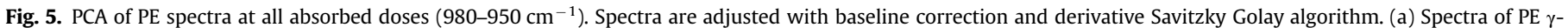

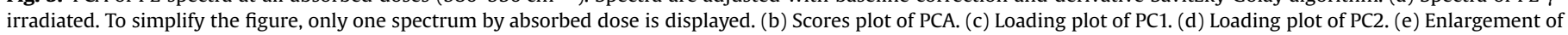
score (b) for $0 \mathrm{kGy}$ group with time labels. (f) Enlargement of score (b) for $270 \mathrm{kGy}$ group with time labels. 
groups, degrades the vinyl end groups and does not alter the vinylidene groups.

PC2 (Fig. 5b, d, e and f) reveals some modifications for the vinylidene groups $\left(890 \mathrm{~cm}^{-1}\right)$, which decrease over time. Trans vinylene groups and vinyl end groups (964 and $908 \mathrm{~cm}^{-1}$, respectively) are not impacted by ageing. The natural ageing of non-irradiated samples does not lead to significant changes in spectra, because the 12-month-aged group (T12months) is close to the T0, T1month and T2months groups. However, after $\gamma$-irradiation of samples, there is an increase in vinylidene groups $\left(890 \mathrm{~cm}^{-1}\right)$ over time. Over time, only the vinylidene groups are altered, which implies that the other unsaturations (trans vinylene groups and vinyl end groups) remain stable. These results do not deserve further comments as agree with literature (Tidjani and Watanabe, 1995; Lacoste and Carlsson, 1992; Dole, 1981; Dole and Patel, 1977; Liu et al., 2011; Wool and Bretzlaff, 1986; Cross et al., 1950; Gugumus, 2000).

\section{Conclusion}

This work highlights two different ageing processes:

- The first one due to the $\gamma$-irradiation, which generates modifications of the polymer, even more so in the presence of oxygen. The carboxylic acids and unsaturated compounds are observed on the film surface. Probably these compounds are also generated in the core of the PE layer, due to the migration of the oxygen through the film.

- The second one due to the natural ageing, which has very little impact - only the peak at $890 \mathrm{~cm}^{-1}$ (vinylidene group) is slightly impacted by ageing.

If there is a migration of by-products from the core to the surface, then it is in trace amounts and therefore not visible by ATR-FTIR. We are aware that there may be changes in the core layer and a further investigations will focus on the mechanical tests and permeability tests.

\section{Acknowledgments}

FG thanks Sartorius Stedim Biotech for PhD Grant. ND and SRAM are thankful to AMU and CNRS for their support, and to Sartorius Stedim Biotech for funding.

\section{Appendix A. Supplementary material}

Supplementary data associated with this article can be found in the online version at http://dx.doi.org/10.1016/j.radphyschem. 2016.03.010.

\section{References}

Audran, G., Dorey, S., Dupuy, N., Gaston, F., Marque, S.R.A., 2015. Degradation of $\gamma$ irradiated polyethylene-ethylene vinyl alcohol-polyethylene multilayer films: an ESR study. Polym. Degrad. Stab. 122, 169-179.

Boerio, F.J., Wirasate, S., 2007. Measurements of the chemical characteristics of polymers and rubbers by vibrational spectroscopy. In: Everall, Neil J., Chalmers, John M., Griffiths, Peter R. (Eds.), Vibrational spectroscopy of Polymers: Principles and Practice. John Wiley and Sons, p. p114.

Bourges, F., Bureau, G., Dumonceau, J., Pascat, B., 1992. Effects of electron beam irradiation on antioxidants in commercial polyolefins: determination and quantification of products formed. Packag. Technol. Sci. 5, 205-209.

Buttafava, A., Tavares, A., Arimondi, M., Zaopo, A., Nesti, S., Dondi, D., Mariani, M., Faucitano, A., 2007. Dose rate effects on the radiation induced oxidation of polyethylene. Nucl. Instrum. Methods B 265, 221-226.

Hemmerich, K.J., 2000. Medical device and diagnostic industry, online: 〈http:// www.mddionline.com/article/polymer-materials-selection-radiation-ster ilized-products $\rangle$.

Cross, L.H., Richards, R.B., Willis, H.A., 1950. The infra-red spectrum of ethylene polymers. Discuss. Faraday Soc. 9, 235-245.

Demertzis, P.G., Franz, R., Welle, F., 1999. The effects of gamma-irradiation on compositional changes in plastic packaging films. Packag. Technol. Sci. 12 119-130.

Dole, M., 1981. A commentary on free radicals and new end groups resulting from chain scission: 1. Gamma irradiation of polyethylene. Polymer 22, 1458-1459.

Dole, M., Patel, V.M., 1977. Comparison of irradiation crosslinking and chain scission in extended chain and bulk film samples of linear polyethylene. Radiat. Phys. Chem. 9, 433-444.

Dole, M., Gupta, C., Gvozdic, N., 1979. Crystallinity and crosslinking efficiency in the irradiation of polyethylene. Radiat. Phys. Chem. 14, 711-720.

Driffield, M., Bradley, E., Castle, L., 2009. Literature review, analytical screening and chemical migration studies on irradiated food packaging.

Esbensen, K.H., Guyot, D., Westad, F., Houmoller, L.P., 2002. Multivariate Data Analysis: in Practice : an Introduction to Multivariate Data Analysis and Experimental Design.

Giurginca, M., Popa, L., Zaharescu, T., 2003. Thermo-oxidative degradation and radio-processing of ethylene vinyl acetate elastomers. Polym. Degrad. Stab. 82, 463-466.

Bioprocess International, 2008. Guide to Irradiation and Sterilization Validation of Single-Use Bioprocess Systems, p. 12.

Goulas, A.E., Riganakos, K.A., Kontominas, M.G., 2003. Effect of ionizing radiation on physicochemical and mechanical properties of commercial multilayer coextruded flexible plastics packaging materials. Radiat. Phys. Chem. 68, 865-872.

Guadagno, L., Naddeo, C., Vittoria, V., Camino, G., Cagnani, C., 2001. Chemical and morphological modifications of irradiated linear low density polyethylene (LLDPE). Polym. Degrad. Stab. 2, 175-186.

Gugumus, F., 2000. Physico-chemical aspects of polyethylene processing in an open mixer 2. Functional group formation on PE-LD processing. Polym. Degrad. Stab. 67, 35-47.

Jeon, D.H., Park, G.Y., Kwak, I.S., Lee, K.H., Park, H.J., 2007. Antioxidants and their migration into food simulants on irradiated LLDPE film. LWT 40, 151-156.

Kaci, M., Djidjelli, H., Boukedami, T., 2008. Study of the effect of gamma irradiation on the structure and properties of metallocene linear low density polyethylene containing hindered amines. Polym. Bull. 60, 387-395.

Klepac, D., Scetar, M., Baranovic, G., Galic, K., Valic, S., 2014. Influence of high doses $\gamma$-irradiation on oxygen permeabilityof linear low-density polyethylene and cast polypropylene films. Radiat. Phys. Chem. 97, 304-312.

Kumar, N., Bansal, A., Sarma, G.S., Rawal, R.K., 2014. Chemometrics tools used in analytical chemistry: an overview. Talanta 123, 186-199.

Lacoste, J., Carlsson, D.J., 1992. Gamma-, photo-, and thermally-initiated oxidation of linear low density polyethylene: a quantitative comparison of oxidation products. J. Polym. Sci. Polym. Chem. 30, 493-500.

Lacoste, J., Carlsson, D.J., Falicki, S., Wiles, D.M., 1991. Polyethylene hydroperoxide decomposition products. Polym. Degrad. Stab. 34, 309-323.

Liu, Z., Chen, S., Zhang, J., 2011. Photodegradation of ethyleneeoctene copolymers with different octene contents. Polym. Degrad. Stab. 96, 1961-1972.

Liu, P., et al., 2013. Environ. Sci. Technol. 47, 13594-13601.

Liu, J.G., et al., 2009. J. Mater. Chem. 19, 8907-8919.

Lobo, H., Bonilla, J.V., 2003. Handbook of Plastics Analysis, pp. 218-220.

Martens, H., Naes, T., 1989. Multivariative Calibration. Wiley.

Pospisil, J., 1993. Chemical and photochemical behaviour of phenolic antioxidants in polymer stabilization-a state of the art report, Part 1. Polym. Degrad. Stab. 40 217-232.

Rjeb, A., Tajounte, L., Chafik el Idrissi, M., Letarte, S., Adnot, A., Roy, D., Claire, Y., Périchaud, A., Kaloustian, J., 2000. IR spectroscopy study of polypropylene natural aging. J. Appl. Polym. Sci. 77, 1742-1748.

Socrates, G., Infrared and Raman Characteristic Group Frequencies, 3rd Edition, (2001), p132.

Socrates, G., Infrared and Raman Characteristic Group Frequencies, 3rd Edition, p124-125.

Socrates, G., Infrared and Raman Characteristic Group Frequencies, 3rd Edition, p117.

Socrates, G., Infrared and Raman Characteristic Group Frequencies, 3rd Edition, p268.

Stoffers, N.H., Linssen, J.P.H., Franz, R., Welle, F., 2004. Migration and sensory evaluation of irradiated polymers. Radiat. Phys. Chem. 71, 203-206.

Suarez, J.C.M., Mano, E.B., 2001. Characterization of degradation on gamma-irradiated recycled polyethylene blends by scanning electron microscopy. Polym. Degrad. Stab. 72, 217-221.

Tabb, D.L., Sevcik, J.J., Koenig, J.L., 1975. Fourier transform infrared study of the effects of irradiation on polyethylene. J. Polym. Sci. Polym. Phys. 13, 815-824.

Taniike, A., Hirooka, Y., Nakanishi, N., Nakamura, R., Furuyama, Y., 2014. High fluence irradiation effect on the ion beam graft polymerization method. Nucl. Instrum. Methods B 331, 191-195.

Tidjani, A., 2000. Comparison of formation of oxidation products during photooxidation of linear low density polyethylene under different natural and accelerated weathering conditions. Polym. Degrad. Stab. 8, 465-469.

Tidjani, A., Arnaud, R., 1993. Gamma-oxidation of linear low density polyethylenes: ethylene-butene and ethylene-hexene copolymers. J. Polym. Sci. Polym. Chem. 31, 603-609. 
Tidjani, A., Watanabe, Y., 1995. Gamma-oxidation of linear low density polyethylenes: the dose-rate effect of irradiation on chemical and physical modifications. J. Polym. Sci. Polym. Chem. 33, 1455-1460.

Traboulsi, A., Dupuy, N., Rebufa, C., Sergent, M., 2012. Investigation of gamma radiation effect on the anion exchange resin Amberlite IRA-400 in hydroxide form by Fourier transformed infrared and ${ }^{13} \mathrm{C}$ nuclear magnetic resonance spectroscopies. Anal. Chim. Acta 717, 110-121.

Wool, R.P., Bretzlaff, R.S., 1986. Infrared and Raman spectroscopy of stressed polyethylene. J. Polym. Sci. Polym. Phys. 24, 1039-1066.

Youssef, B., Elkader Dehbi, A., Hamou, A., Saiter, J.-M., 2008. Natural ageing of trilayer polyethylene film: evolution of properties and lifetime in North Africa region. Mater. Des. 29, 2017-2022. 